\title{
Morphological diversity of the tricuspid posterior leaflet affects surgical complexity for control of tricuspid regurgitation
}

\author{
takumi kawase $^{1}$, Yosuke Takahashi ${ }^{1}$, Kenta Nishiya ${ }^{1}$, Noriaki Kishimoto ${ }^{1}$, Kokoro \\ Yamane $^{1}$, Yoshito Sakon ${ }^{1}$, Akimasa Morisaki ${ }^{1}$, Hiromichi Fujii ${ }^{1}$, and Toshihiko Shibata ${ }^{1}$ \\ ${ }^{1}$ Osaka City University Graduate School of Medicine School of Medicine
}

July 29, 2021

\begin{abstract}
Abstract Objective: We investigated the effect of morphological diversity of the tricuspid valve with multiple posterior leaflets on the technical outcomes of tricuspid valve repair. Methods: From April 2016 to November 2020, 141 patients were diagnosed with secondary tricuspid regurgitation associated with left heart disease and underwent tricuspid valve repair. We retrospectively analyzed the clinical and echocardiographic data of patients who underwent both preoperative and postoperative transthoracic echocardiography. We divided the patients into two groups according to the surgical technique used to treat tricuspid regurgitation: ring annuloplasty alone (Group 1, $\mathrm{n}=109$ ) or additional approximation of leaflet edges (edge-to-edge repair) with ring annuloplasty (Group 2, $\mathrm{n}=32$ ). We measured the morphological diversity of the tricuspid valve during the operation in all

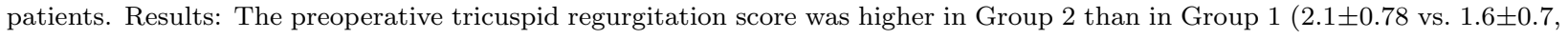
respectively; $\mathrm{p}=0.0046)$, and Group 2 contained more patients with two posterior leaflets than Group 1 [20 (63\%) vs. 36 (33\%), respectively; $\mathrm{p}=0.003]$. The univariate and multivariate logistic regression analyses showed that the presence of two posterior leaflets was an independent risk factor for additional procedures during tricuspid valve repair (odds ratio, 2.6; 95\% confidence interval, 1.1-6.1; $\mathrm{p}=0.033$ ). Conclusions: Additional procedures to reduce tricuspid regurgitation were required more frequently in patients with two posterior leaflets of the tricuspid valve. The morphological diversity of two posterior leaflets is a potential risk factor for a more complicated tricuspid repair.
\end{abstract}

\section{Introduction}

Several studies have focused on the anatomy and pathophysiology of secondary tricuspid regurgitation (TR) associated with left heart disease or atrial fibrillation $(1,2)$. Patients with significant TR, especially that in the severe range, have a poor prognosis $(3,4)$. Surgical treatment can produce excellent results in patients with severe TR that medical treatment is unable to control $(4,5)$. However, patients requiring reoperation because of significant residual or recurrent TR have a poor prognosis with high mortality (6). Therefore, it is very important to address TR during the operation and analyze the risk factors for residual TR after tricuspid valve (TV) repair (7-9).

Sakon et al. (10) recently demonstrated that the number of posterior leaflets was two or more in a half of the patients analyzed in their study. However, no studies have shown that morphological diversity of the TV affects the outcomes and surgical techniques of TV repair. The present study was performed to investigate the effect of morphological diversity of the TV on the difficulty of controlling TR during TV repair.

\section{Materials and Methods}

This study was approved by the Osaka City University Ethical Review Board (approval no. 3556). Informed consent was obtained from all patients using an opt-out method. 
From April 2016 to November 2020, 187 patients were diagnosed with secondary TR associated with left heart disease and underwent TV repair. Indication of TV repair was followed the 2020 Japan JCS/JSCS/JATS/JSVS Guideline (11).

All patients underwent tricuspid annuloplasty using a Carpentier-Edwards Physio Tricuspid Annuloplasty Ring (Edwards Lifesciences, Irvine, CA, USA) or Tailor Flexible Annuloplasty Ring (Abbott, Menlo Park, CA, USA). The exclusion criteria were infective endocarditis and primary TR. Patients without perioperative echocardiographic data and patients who underwent re-do TV repair were also excluded. Finally, we analyzed 141 patients with secondary TR due to TV annular dilatation (Fig.1).

We divided the patients into two groups: Group 1 comprised patients who underwent only ring annuloplasty for TR, and Group 2 comprised patients who required additional approximation of leaflet edges (edgeto-edge repair) with ring annuloplasty to reduce residual TR. We retrospectively examined the patients' background data, preoperative transthoracic echocardiography data, surgical procedures, and anatomical features of the posterior leaflets and compared these data between the two groups. We also analyzed the risk predictors of the need for additional procedures to reduce TR. Finally, we assessed preoperative and postoperative echocardiographic parameters between patients with one posterior valve leaflet and patients with two posterior valve leaflets.

\section{Echocardiography}

All patients underwent transthoracic echocardiography using an iE33 or EPIQ system (Philips Medical Systems, Andover, MA, USA) at our echocardiography laboratory preoperatively, 1 week and 1year postoperatively.

The TR grade was defined using a multiparametric approach, including an assessment of the color Dopplerderived jet area, the continuous wave Doppler-derived jet density and contour, and the hepatic vein flow velocity pattern (12). TR was graded as none, trivial, mild, moderate, or severe. For the statistical analysis, these TR grades were scored as follows: none $=0$, none to mild $=0.5$, mild $=1$, mild to moderate $=1.5$, moderate $=2$, moderate to severe $=2.5$, and severe $=3(13)$.

Continuous wave Doppler was used to obtain the TR peak velocity $(\mathrm{m} / \mathrm{s})$ and the transtricuspid systolic pressure gradient (TRPG, $\mathrm{mmHg}$ ), which was calculated as $4 \mathrm{~V}^{2}$ (where $\mathrm{V}$ is velocity). The right ventricular systolic pressure was then estimated as the sum of the estimated TRPG and right atrial (RA) pressure. The RA pressure was estimated as follows: an inferior vena cava diameter of [?]2.1 $\mathrm{cm}$ that collapsed by [?] $50 \%$ when the patient sniffed was considered to indicate a normal RA pressure of $3 \mathrm{mmHg}$, whereas an inferior vena cava (IVC) diameter of $>2.1 \mathrm{~cm}$ that collapsed by $<50 \%$ when the patient sniffed was considered to indicate a high RA pressure of $15 \mathrm{mmHg}$. When the IVC diameter and collapse did not fit this paradigm, an intermediate value of $8 \mathrm{mmHg}$ was assigned (14). An estimated right ventricular systolic pressure of $>40$ $\mathrm{mmHg}$ was considered indicative of pulmonary hypertension (15). Tricuspid annular diameter was measured at end-diastole and annular diameter of $>40 \mathrm{~mm}$ or $21 \mathrm{~mm} / \mathrm{m}^{2}$ was considered significant annulus dilatation (11). The RA dimension, left ventricular (LV) end-diastolic dimension, LV end-systolic dimension, LV ejection fraction, and left atrial (LA) dimension were measured according to the established guidelines $(14,16)$.

\section{Surgical technique}

In all patients, cardiopulmonary bypass was established by ascending aortic cannulation and bicaval venous drainage through a median sternotomy. TV repair was performed concomitantly with aortic valve replacement or a mitral valve procedure in all cases. After the aortic or mitral valve procedure, we performed TV repair under cardiac arrest. The number of leaflets was determined according to the definition established by Silver et al. (17): The commissure is defined as an indentation of the leaflets by fan-shaped chordae, the fanshaped chordae forming the anteroposterior commissure arise from the anterior papillary muscle, and the posteroseptal commissure is defined by the fan-shaped chordae, which arise from the most medially placed papillary muscle on the posterior wall $(10,17)$ (Fig. 2).

All patients underwent tricuspid ring annuloplasty using either 2-0 polyester interrupted sutures for the 
Carpentier-Edwards Physio Tricuspid Annuloplasty Ring or 2-0 polyester running sutures for the Tailor Flexible Annuloplasty Ring. To prevent atrioventricular node injury, we avoided placing sutures around the septal leaflet's annulus near the atrioventricular node when using the Tailor Flexible Annuloplasty Ring (Fig. 3). The Carpentier-Edwards Physio Tricuspid Annuloplasty Ring or the Tailor Flexible Annuloplasty Ring was used according to the surgeon's preference. The ring size was determined comprehensively by measuring the area of the anterior leaflet or annular distance of the septal leaflet using the sizers for each ring.

Upon completion of the ring annuloplasty, we checked for residual TR using the saline test. During the saline test, a surgeon compressed the pulmonary artery by hand from the outside to fill the right ventricle sufficiently. Results of the saline test was classed as follows; (a) good shape (The height of all TV leaflets was aligned. All leaflets had adequate tension and coaptation.) with no leakage (Fig. 3), (b) good shape with leakage, and (c) poor shape (The height of some TV leaflets was different and tension of leaflets was insufficient.) with leakage (Fig.4). We judged (c) as residual TR. If residual TR between the leaflets was found, we performed additional techniques to approximate leaflet edges (edge-to-edge repair). (Video)

After weaning from cardiopulmonary bypass, TR was checked by intraoperative transesophageal echocardiography.

\section{Statistical analysis}

Descriptive statistics for categorical variables are reported as absolute value and percentage, and continuous variables are shown as mean and standard deviation. Categorical data were compared using the chi-square test. Continuous variables were compared using the Wilcoxon signed rank test.

We analyzed independent determinants of the additional procedure by performing univariate logistic regression analysis and subsequent multivariate logistic regression analysis, with the p values for entry into and removal from the model set at 0.05 and 0.10 , respectively. All analyses were conducted with JMP version 13.0 (SAS Institute Inc., Cary, NC, USA), and a p value of $<0.05$ was considered statistically significant.

\section{Results}

Patient's profiles (Table 1)

A total of $32(23 \%)$ patients needed an additional procedure with ring annuloplasty to reduce TR. There was no significant difference in the patients' preoperative background data between the two groups.

There was no statistically significant difference in the cardiac dimension, the TRPG and the TV diameter between the two groups. The preoperative TR score was higher ( $2.1 \pm 0.78$ vs. $1.6 \pm 0.7 ; \mathrm{p}=0.0046)$, and more patients had pulmonary hypertension [19 (61\%) vs. $41(38 \%) ; \mathrm{p}=0.019]$ in Group 2 than in Group 1, respectively.

\section{Surgical data (Table 2)}

A total of $56(40 \%)$ patients had two posterior leaflets of the TV. The proportion of patients with two posterior leaflets was higher in Group 2 than in Group 1 [20 (63\%) vs. 36 (33\%), respectively; p=0.003]. All patients underwent TV ring annuloplasty. There was no statistically significant difference in the ring type or ring size between the two groups. Aortic valve replacement (AVR) was more frequently performed as a concomitant procedure in Group 1 than in Group 2 [41 (38\%) vs. 5 (16\%), respectively; $\mathrm{p}=0.014]$.

\section{Additional procedures}

Edge-to-edge repair was performed in all patients in Group 2.

There were 25 cases with one edge-to-edge repair in Group 2 (4 cases with edge-to-edge at anterior and posterior leaflets, 11 cases at posterior and septal leaflets, 9 cases at anterior and septal leaflets, and 1 case at posterior and posterior leaflets). There were 6 cases with 2 edge-to-edge repairs in Group 2 (3 cases with edge to edge at the anterior-posterior leaflet and posterior-septal leaflet, 2 cases at the anterior-septal leaflet and posterior-septal leaflet, and 1 case at the anterior-septal leaflet and posterior-posterior leaflet). 
One patient in Group 2 underwent three edge-to-edge repairs at the anterior-septal leaflet, anterior-posterior leaflet, and posterior-septal leaflet.

In all patients in both groups, TR was controlled, confirmed by the intraoperative saline test. The 1-week postoperative TR score in all 141 patients decreased, confirmed by echocardiography. TR score improved from $1.6 \pm 0.7$ to $0.7 \pm 0.32(\mathrm{p}<0.0001)$ in Group 1 and from $2.1 \pm 0.78$ to $0.88 \pm 0.49(\mathrm{p}<0.0001)$ in Group 2 .

\section{Postoperative transthoracic echocardiographic data (Table 3)}

All patients underwent transthoracic echocardiography 1 week after surgery. There was no statistically significant difference in the cardiac dimensions between the two groups. The postoperative TR score $(0.88$ \pm 0.49 vs. $0.7 \pm 0.32 ; \mathrm{p}=0.043)$ and the TRPG $(24 \pm 14 \mathrm{mmHg}$ vs. $19 \pm 11 \mathrm{mmHg} ; \mathrm{p}=0.05)$ were higher in Group 2 than in Group 1, respectively.

\section{Predictors of additional procedures (Table 4)}

Table 4 shows the results of the univariate and multivariate logistic regression analyses to identify the predictors of the need for additional procedures. In the model using echocardiographic data and clinical data, the preoperative TR score (odds ratio, 1.8; 95\% confidence interval, 1.0-3.4; $\mathrm{p}=0.042$ ) and the presence of a $\mathrm{TV}$ with two posterior leaflets (odds ratio, 2.6;95\% confidence interval, 1.1-6.1; $\mathrm{p}=0.033$ ) were independent predictors of additional procedures, according to the multivariate analysis

\section{Comparison of echocardiographic parameters for each number of posterior leaflets (Table 5)}

There was no significant difference between patients with one posterior valve leaflet and patients with two posterior valve leaflets regarding cardiac dimension in perioperative periods. Patients with two posterior valve leaflets had better cardiac $\mathrm{LV}$ contraction than those with one posterior valve leaflet before operation $(58 \% \pm 9.2 \%$ vs. $53 \% \pm 12 \%$, respectively; $\mathrm{p}=0.014)$. There were also no significant differences in the TRPG, the number of patients with pulmonary hypertension and the TV diameter. However, the presence of two posterior valve leaflets was associated with a higher preoperative TR score than one posterior valve leaflet (1.9 \pm 0.81 vs. $1.6 \pm 0.67$, respectively; $\mathrm{p}=0.032$ ). Regarding echocardiographic parameters after operation, there was no difference of TR score just after surgery between groups, but two posterior leaflets cases had higher TR score than one posterior leaflet cases one year after operation ( $0.95 \pm 0.43$ vs. $0.7 \pm 0.3$, respectively; $\mathrm{p}=0.0075)$.

\section{Discussion}

In the present study, a TV with two posterior leaflets was an independent predictor of additional procedures. The TV consists of multiple posterior leaflets in about half of patients, and the morphological diversity of these leaflets has attracted attention among researchers $(10,17,18)$.

We consider that postoperative TR can be divided into two types: TR observed immediately after surgery (residual TR) and TR that worsens during follow-up despite the fact that it was controlled immediately after surgery (recurrent TR). Fukuda et al. (9) reported that residual TR soon after the operation causes volume overloading of the right ventricle and further right ventricular dilatation and dysfunction, resulting in worsening TR. Therefore, we consider that controlling the residual TR grade during the perioperative period is crucial to avoid the development of later TR.

Upon completion of the ring annuloplasty, we routinely checked TV by the saline test. If residual TR was found, we performed additional edge-to-edge repair at the sites of the leakage. Although we could control TR with ring annuloplasty alone in most patients, additional sutures were necessary to control residual TR in some patients. The locations and numbers of edge-to-edge repairs varied among the patients according to the features of the residual TR. Thus, we investigated the crucial causes of complicated TV repair in our study.

The surgical technique to control TR depends upon the mechanism of TR, such as annular dilatation, prolapse 
or tethering of the leaflets, or right ventricular dilatation. We suspected that morphological differences of the TV may make it difficult to control TR during surgery. Therefore, we focused on TV morphology and the complexity, to control TR. We set the endpoint as whether additional procedures were needed during the operation. According to the univariate and multivariate logistic regression analyses, patients with two posterior valve leaflets required additional procedures for reduction of TR. Moreover, patients with two posterior valve leaflets had higher TR score before operation and one year after operation than those with one posterior valve leaflet. There was no difference in the size of the TV regardless of the number of posterior leaflets. Considering these results, we concluded that the presence of two posterior valve leaflets itself has the potential to increase regurgitation, resulting in the need for complex procedures in TV repair.

When we classify the morphological diversity of the TV leaflets, identification of the commissure between the anterior and posterior leaflets is important. When the TV has two posterior leaflets, the commissural cleft between the anterior and posterior leaflets is sometimes misidentified as a deep cleft of the anterior leaflet. This is because most surgeons do not observe fan-shaped chordae arising from the anterior papillary muscle and do not recognize that half of patients have a TV with two posterior leaflets. When surgeons misinterpret the commissure between the anterior and posterior leaflets, they might choose a smaller annuloplasty ring and adjust the marker on the ring to an inappropriate position, especially in patients with two posterior leaflets. A smaller ring might deform TV annulus and impose more stress on suture lines. We measured both the distance between the commissure of the septal leaflet and the area of the anterior leaflet for proper sizing of annuloplasty ring, resulting in selection of larger ring. To avoid deformation of the TV, we applied the "shoulder point fitting method" of proportional annuloplasty in all patients (18). The shoulder point is defined as the 2-o'clock position of the TV annulus, where the TV annulus is more widely dilated. This technique has a lower risk of TV annulus deformation because annuloplasty is performed toward the shoulder point (18). This method also supports patients with multiple posterior leaflets. We are convinced that proportional annuloplasty was achieved in all patients regardless of the number of posterior leaflets in this study.

\section{Limitations}

Our study has several limitations. First, it was retrospective and involved a small number of patients. Therefore, the differences in the patients' backgrounds between the two groups could not be statistically adjusted. This issue should be addressed in future prospective studies containing larger numbers of patients. Second, we used two types of rings and two types of suturing techniques when performing TV repair. The type of ring and technique should be unified in future studies. Third, we could not clarify the mechanism of residual TR in patients with posterior leaflets in spite of using shoulder point fitting method. Finally, because our study was limited to the perioperative results, further evaluation should also involve the midterm follow-up period.

\section{Conclusion}

The morphological diversity of two posterior leaflets is a potential risk factor that makes TV repair complicated and that leaves residual TR.

\section{Funding}

None

\section{Conflict of interest}

None declared.

\section{Figure legends}

Fig. 1 Flow diagram of patient selection

$T R$, tricuspid regurgitation

Fig. 2 Operative findings of tricuspid valve with two posterior leaflets 
$A$, anterior leaflet; $P 1$ and $P \mathscr{2}$, posterior leaflets; $S$, septal leaflet

Fig. 3 The Tailor ring was sutured with the running suture technique

We avoided placing sutures around the septal leaflet's annulus near the atrioventricular node. We confirmed significant coaptation of each valve by the saline injection test.

The blue arrow indicates the shoulder point. $A$, anterior leaflet; $P$, posterior leaflet; $S$, septal leaflet

Fig. 4 saline test after tricuspid valve repair

A: Motion of septal leaflet was restricted and all leaflets could not have same coaptation height.

B: Only one posterior leaflet raised and other leaflets did not get adequate tension. There were gaps between a posterior leaflet and other leaflets.

The yellow arrow indicated restricted septal leaflet. The red arrow indicated different height of posterior leaflet.

Video

The TV has two posterior leaflets. After ring annuloplasty, we checked TV by saline test. A posterior leaflet raised and there were gaps between the posterior leaflet and other leaflets.

A 5-0 polypropylene suture was placed to approximate at posterior and posterior leaflets.

Table 1. Patient characteristics

\begin{tabular}{|c|c|c|c|}
\hline & Group $1(n=109)$ & Group $2(n=32)$ & p value \\
\hline Preoperative & Preoperative & Preoperative & Preoperative \\
\hline characteristics & characteristics & characteristics & characteristics \\
\hline Male sex & $63(58)$ & $14(44)$ & 0.16 \\
\hline Age, years & $71 \pm 9.2$ & $72 \pm 10$ & 0.51 \\
\hline $\begin{array}{l}\text { Body surface area, } \\
\text { m }^{2}\end{array}$ & $1.6 \pm 0.2$ & $1.5 \pm 0.18$ & 0.22 \\
\hline $\begin{array}{l}\text { NYHA class [?]II } \\
\text { heart failure }\end{array}$ & $96(88)$ & $30(94)$ & 0.33 \\
\hline Comorbidities & Comorbidities & Comorbidities & Comorbidities \\
\hline Atrial fibrillation & $73(67)$ & $24(75)$ & 0.38 \\
\hline Systemic & $60(55)$ & $21(66)$ & 0.28 \\
\hline \multicolumn{4}{|l|}{ hypertension } \\
\hline Dyslipidemia & $23(21)$ & $11(34)$ & 0.13 \\
\hline Diabetes mellitus & $16(15)$ & $8(25)$ & 0.19 \\
\hline Cerebrovascular & $21(19)$ & $9(28)$ & 0.29 \\
\hline \multicolumn{4}{|l|}{ event } \\
\hline $\begin{array}{l}\text { Ischemic heart } \\
\text { disease }\end{array}$ & $18(17)$ & $10(31)$ & 0.077 \\
\hline Chronic renal & $35(32)$ & $14(44)$ & 0.23 \\
\hline \multicolumn{4}{|l|}{ failure } \\
\hline COPD & $7(6.4)$ & $2(6.3)$ & 0.97 \\
\hline Preoperative & Preoperative & Preoperative & Preoperative \\
\hline transthoracic & transthoracic & transthoracic & transthoracic \\
\hline echocardiographic & echocardiographic & echocardiographic & echocardiographic \\
\hline data & data & data & data \\
\hline $\begin{array}{l}\text { RA minimum } \\
\text { (4-chamber view), } \\
\text { mm }\end{array}$ & $42 \pm 11$ & $45 \pm 11$ & 0.11 \\
\hline
\end{tabular}




\begin{tabular}{|c|c|c|c|}
\hline & Group $1(n=109)$ & Group $2(n=32)$ & $\mathrm{p}$ value \\
\hline $\begin{array}{l}\text { RA maximum } \\
\text { (4-chamber view), } \\
\text { mm }\end{array}$ & $61 \pm 13$ & $65 \pm 17$ & 0.32 \\
\hline LVEF, \% & $55 \pm 11$ & $55 \pm 14$ & 0.36 \\
\hline $\begin{array}{l}\text { LVDd (parasternal } \\
\text { long-axis view), mm }\end{array}$ & $51 \pm 8.3$ & $50 \pm 9.2$ & 0.44 \\
\hline $\begin{array}{l}\text { LVDs (parasternal } \\
\text { long-axis view), mm }\end{array}$ & $34 \pm 8.9$ & $33 \pm 9.5$ & 0.6 \\
\hline $\begin{array}{l}\text { LA (parasternal } \\
\text { long-axis view), mm }\end{array}$ & $52 \pm 10$ & $55 \pm 13$ & 0.58 \\
\hline Pre TR score & $1.6 \pm 0.7$ & $2.1 \pm 0.78$ & 0.0046 \\
\hline TRPG, mmHg & $32 \pm 13$ & $37 \pm 16$ & 0.13 \\
\hline $\begin{array}{l}\text { PH (estimated } \\
\text { RVSP of }>40 \\
\text { mmHg) }\end{array}$ & $41(38)$ & $19(61)$ & 0.019 \\
\hline $\begin{array}{l}\text { TV diameter, } \\
\mathrm{mm} / \mathrm{m}^{2}\end{array}$ & $24 \pm 4.7$ & $24 \pm 4.3$ & 0.69 \\
\hline
\end{tabular}

Group 1: Patients who underwent ring annuloplasty alone

Group 2: Patients who required additional edge-to-edge repair with ring annuloplasty

Data are presented as n (\%) or mean \pm standard deviation.

NYHA , New York Heart Association; COPD , chronic obstructive pulmonary disease; RA, right atrium; $L V E F$, left ventricular ejection fraction; $L V D d$, left ventricular diastolic dimension; $L V D s$, left ventricular systolic dimension; $L A$, left atrium; Pre TR score, preoperative tricuspid regurgitation score; TRPG, transtricuspid pressure gradient; $P H$, pulmonary hypertension (estimated right ventricular systolic (RSVP ) pressure $>40 \mathrm{mmHg}$ ); $T V$, tricuspid valve

Table 2. Surgical data

\begin{tabular}{|c|c|c|c|}
\hline & Group $1(n=109)$ & Group $2(n=32)$ & $p$ value \\
\hline $\begin{array}{l}\text { Morphological } \\
\text { diversity }\end{array}$ & $\begin{array}{l}\text { Morphological } \\
\text { diversity }\end{array}$ & $\begin{array}{l}\text { Morphological } \\
\text { diversity }\end{array}$ & $\begin{array}{l}\text { Morphological } \\
\text { diversity }\end{array}$ \\
\hline $\begin{array}{l}\text { Valve with two } \\
\text { posterior leaflets }\end{array}$ & $36(33)$ & $20(63)$ & 0.003 \\
\hline Annuloplasty ring & Annuloplasty ring & Annuloplasty ring & Annuloplasty ring \\
\hline Carpentier-Edwards & $76(70)$ & $26(81)$ & 0.19 \\
\hline \multicolumn{4}{|l|}{ Physio Tricuspid } \\
\hline \multicolumn{3}{|l|}{ Annuloplasty Ring } & \\
\hline \multicolumn{4}{|l|}{ Annuloplasty Ring } \\
\hline Ring size, mm & $29 \pm 1.8$ & $29 \pm 1.7$ & 0.19 \\
\hline $\begin{array}{l}\text { Concomitant } \\
\text { procedures }\end{array}$ & $\begin{array}{l}\text { Concomitant } \\
\text { procedures }\end{array}$ & $\begin{array}{l}\text { Concomitant } \\
\text { procedures }\end{array}$ & $\begin{array}{l}\text { Concomitant } \\
\text { procedures }\end{array}$ \\
\hline AVR & $41(38)$ & $5(16)$ & 0.014 \\
\hline MVP & $47(43)$ & $15(47)$ & 0.71 \\
\hline MVR & $45(41)$ & $16(50)$ & 0.38 \\
\hline
\end{tabular}




\begin{tabular}{llll}
\hline & Group 1 $(\mathbf{n}=\mathbf{1 0 9})$ & Group 2 $(\mathbf{n}=\mathbf{3 2})$ & p value \\
\hline $\begin{array}{l}\text { AVR or MVP or } \\
\text { MVR }+ \text { maze }\end{array}$ & $32(29)$ & $6(19)$ & 0.22 \\
procedure & & & \\
\hline
\end{tabular}

Group 1: Patients who underwent ring annuloplasty alone

Group 2: Patients who required additional edge-to-edge repair with ring annuloplasty

Data are presented as n (\%) or mean \pm standard deviation.

$A V R$, aortic valve replacement; $M V P$, mitral valve repair; $M V R$, mitral valve replacement

Table 3. Postoperative transthoracic echocardiographic data

\begin{tabular}{|c|c|c|c|}
\hline & Group $1(n=109)$ & Group $2(n=32)$ & $p$ value \\
\hline $\begin{array}{l}\text { RA minimum } \\
\text { (4-chamber view), } \\
\text { mm }\end{array}$ & $36 \pm 6.1$ & $36 \pm 6.7$ & 0.74 \\
\hline $\begin{array}{l}\text { RA maximum } \\
\text { (4-chamber view), } \\
\text { mm }\end{array}$ & $49 \pm 8.5$ & $47 \pm 8.4$ & 0.54 \\
\hline LVEF, \% & $52 \pm 11$ & $52 \pm 12$ & 0.81 \\
\hline $\begin{array}{l}\text { LVDd (parasternal } \\
\text { long-axis view), } \mathrm{mm}\end{array}$ & $48 \pm 7.4$ & $47 \pm 7.7$ & 0.32 \\
\hline $\begin{array}{l}\text { LVDs (parasternal } \\
\text { long-axis view), } \mathrm{mm}\end{array}$ & $32 \pm 8.2$ & $32 \pm 7.9$ & 0.72 \\
\hline $\begin{array}{l}\text { LA (parasternal } \\
\text { long-axis view), } \mathrm{mm}\end{array}$ & $46 \pm 8.5$ & $46 \pm 8.4$ & 0.46 \\
\hline Post TR score & $0.7 \pm 0.32$ & $0.88 \pm 0.49$ & 0.043 \\
\hline TRPG, mmHg & $19 \pm 11$ & $24 \pm 14$ & 0.05 \\
\hline $\begin{array}{l}\text { PH (estimated } \\
\text { RVSP >40 } \mathrm{mmHg} \text { ) }\end{array}$ & $0(0)$ & $0(0)$ & \\
\hline
\end{tabular}

Group 1: Patients who underwent ring annuloplasty alone

Group 2: Patients who required additional edge-to-edge repair with ring annuloplasty

Data are presented as n (\%) or mean \pm standard deviation.

$R A$, right atrium; $L V E F$, left ventricular ejection fraction; $L V D d$, left ventricular diastolic dimension; $L V D s$ , left ventricular systolic dimension; $L A$, left atrium; Pre TR score, preoperative tricuspid regurgitation score; TRPG, transtricuspid pressure gradient; $P H$, pulmonary hypertension (estimated right ventricular systolic pressure $(R S V P)>40 \mathrm{mmHg})$

Table 4. Univariate and multivariate logistic regression analyses of the risk predictors of requiring additional procedures

\begin{tabular}{lll}
\hline & Univariate analysis & Univariate analysis \\
\hline & OR & $95 \%$ CI \\
Model using echocardiographic data & Model using echocardiographic data & Model using echocardiograph \\
Pre TR score & 2.3 & $1.3-4.1$
\end{tabular}




\begin{tabular}{lll}
\hline & Univariate analysis & Univariate analysis \\
\hline PH (estimated RVSP of $>$ 40 $\mathbf{~ m m H g})$ & 2.6 & $1.2-6.0$ \\
RA minimum (4-chamber view) & 1.0 & $0.99-1.1$ \\
RA maximum (4-chamber view) & 1.0 & $0.99-1.0$ \\
TRPG & 1.0 & $0.99-1.0$ \\
LVDd (parasternal long-axis view) & 0.99 & $0.94-1.0$ \\
LVDs (parasternal long-axis view) & 0.98 & $0.95-1.0$ \\
TV diameter, mm/ m² & 0.97 & $0.89-1.1$ \\
Model using clinical data & Model using clinical data & Model using clinical data \\
Valve with two posterior leaflets & 3.4 & $1.5-7.7$ \\
Male sex & 0.56 & $0.26-1.3$ \\
Body surface area & 0.22 & $0.026-1.9$ \\
Age & 1.0 & $0.96-1.1$ \\
NYHA class [?]II heart failure & 2.0 & $0.43-9.5$ \\
Atrial fibrillation & 1.5 & $0.61-3.6$ \\
Dyslipidemia & 2.0 & $0.82-4.6$ \\
Ischemic heart disease & 2.3 & $0.93-5.7$ \\
\hline
\end{tabular}

$O R$, odds ratio; $C I$, confidence interval; PreTR score, preoperative tricuspid regurgitation score; $P H$, pulmonary hypertension (estimated right ventricular systolic pressure $>40 \mathrm{mmHg}$ ); RVSP , right ventricular systolic pressure; $R A$, right atrium; TRPG , transtricuspid pressure gradient; $L V D d$, left ventricular diastolic dimension; $L V D s$, left ventricular systolic dimension; $T V$, tricuspid valve; NYHA, New York Heart Association

Table 5. Perioperative echocardiographic parameters for each number of valve leaflets

Preoperative data

RA minimum (4-chamber view), mm

RA maximum (4-chamber view), mm

LVEF, \%

LVDd (parasternal long-axis view), mm

LVDs (parasternal long-axis view), mm

LA (parasternal long-axis view), $\mathbf{m m}$

Pre TR score

TRPG, mmHg

PH (estimated RVSP $>40 \mathrm{mmHg}$ )

TV diameter, $\mathrm{mm} / \mathrm{m}^{2}$

Postoperative data

RA minimum (4-chamber view), mm

RA maximum (4-chamber view), $\mathrm{mm}$

LVEF, \%

LVDd (parasternal long-axis view), mm

LVDs (parasternal long-axis view), $\mathbf{m m}$

LA (parasternal long-axis view), $\mathbf{m m}$

Post TR score

TRPG, mmHg

One year after operation data

RA minimum (4-chamber view), $\mathrm{mm}$

RA maximum (4-chamber view), $\mathrm{mm}$ LVEF, \%

\begin{tabular}{lll}
\hline $\begin{array}{l}\text { One posterior valve leaflet } \\
\mathbf{n}=\mathbf{8 5}\end{array}$ & $\begin{array}{l}\text { Two posterior valve leaflets } \\
\mathbf{n = 5 6}\end{array}$ & $\mathbf{p}$ value \\
$42 \pm 11$ & $43 \pm 11$ & \\
$62 \pm 13$ & $63 \pm 16$ & 0.51 \\
$53 \pm 12$ & $58 \pm 9.2$ & 0.86 \\
$51 \pm 8.2$ & $52 \pm 8.9$ & 0.014 \\
$33 \pm 9.1$ & $34 \pm 8.9$ & 0.34 \\
$52 \pm 10$ & $54 \pm 12$ & 0.76 \\
$1.6 \pm 0.67$ & $1.9 \pm 0.81$ & 0.25 \\
$34 \pm 15$ & $32 \pm 12$ & 0.032 \\
$32(38)$ & $28(51)$ & 0.61 \\
$24 \pm 4.5$ & $25 \pm 4.7$ & 0.12 \\
$\mathbf{n}=\mathbf{8 5}$ & $\mathbf{n}=\mathbf{5 6}$ & 0.42 \\
$36 \pm 6.3$ & $35 \pm 6.3$ & \\
$48 \pm 8.0$ & $49 \pm 9.2$ & 0.89 \\
$52 \pm 12$ & $53 \pm 10$ & 0.46 \\
$48 \pm 7.3$ & $48 \pm 7.8$ & 0.82 \\
$32 \pm 8.5$ & $32 \pm 7.6$ & 0.96 \\
$45 \pm 7.7$ & $46 \pm 9.5$ & 0.97 \\
$0.76 \pm 0.36$ & $0.71 \pm 0.4$ & 0.77 \\
$21 \pm 11$ & $19 \pm 12$ & 0.58 \\
$\mathbf{n}=\mathbf{4 9}$ & $\mathbf{n}=\mathbf{2 9}$ & 0.41 \\
$36 \pm 6.0$ & $39 \pm 5.7$ & \\
$47 \pm 8.7$ & $50 \pm 8.3$ & 0.1 \\
$54 \pm 9.6$ & $55 \pm 7.7$ & 0.12 \\
& & 0.76
\end{tabular}


LVDd (parasternal long-axis view), $\mathrm{mm}$

LVDs (parasternal long-axis view), $\mathbf{m m} \quad 30 \pm 8.0$

LA (parasternal long-axis view), mm $46 \pm 8.4$

Post TR score $\quad 0.7 \pm 0.3$

TRPG, mmHg
$46 \pm 5.7$

$30 \pm 5.2$

$47 \pm 12$

$0.95 \pm 0.43$

$26 \pm 14$
0.89

0.34

0.95

0.0075

0.1

Data are presented as n (\%) or mean \pm standard deviation.

$R A$, right atrium; $L V E F$, left ventricular ejection fraction; $L V D d$, left ventricular diastolic dimension; $L V D s$, left ventricular systolic dimension; $L A$, left atrium; Pre TR score, preoperative tricuspid regurgitation score; Post TR score, postoperative tricuspid regurgitation score; TRPG, transtricuspid pressure gradient; $P H$, pulmonary hypertension (estimated right ventricular systolic pressure $(R S V P)>40 \mathrm{mmHg}$ ); $T V$, tricuspid valve

\section{References}

1. Silbiger JJ. Atrial functional tricuspid regurgitation: an underappreciated cause of secondary tricuspid regurgitation. Echocardiography 2019;36:954-7.

2. Utsunomiya H, Itabashi Y, Mihara H, Berdejo J, Kobayashi S, Siegel RJ et al. Functional tricuspid regurgitation caused by chronic atrial fibrillation: a real-time 3-dimensional transesophageal echocardiography study. Circ Cardiovasc Imaging 2017;10:e004897.

3. Santoro C, Marco Del Castillo A, González-Gómez A, Monteagudo JM, Hinojar R, Lorente A et al. Mid-term outcome of severe tricuspid regurgitation: are there any differences according to mechanism and severity? Eur Heart J Cardiovasc Imaging 2019;20:1035-42.

4. Lee JW, Song JM, Park JP, Kang DH, Song JK. Long-term prognosis of isolated significant tricuspid regurgitation. Circ J 2010;74:375-80.

5. Nickenig G, Kowalski M, Hausleiter J, Braun D, Schofer J, Yzeiraj E et al. Transcatheter treatment of severe tricuspid regurgitation with the edge-to-edge MitraClip technique. Circulation 2017;135:1802-14.

6. Bernal JM, Morales D, Revuelta C, Llorca J, Gutiérrez-Morlote J, Revuelta JM. Reoperations after tricuspid valve repair. J Thorac Cardiovasc Surg 2005;130:498-503.

7. Ratschiller T, Guenther T, Guenzinger R, Noebauer C, Kehl V, Gertler R et al. Early experiences with a new three-dimensional annuloplasty ring for the treatment of functional tricuspid regurgitation. Ann Thorac Surg 2014;98:2039-44.

8. Navia JL, Nowicki ER, Blackstone EH, Brozzi NA, Nento DE, Atik FA et al. Surgical management of secondary tricuspid valve regurgitation: annulus, commissure, or leaflet procedure? J Thorac Cardiovasc Surg 2010;139:1473-82.

9. Fukuda S, Gillinov AM, McCarthy PM, Stewart WJ, Song JM, Kihara T et al. Determinants of recurrent or residual functional tricuspid regurgitation after tricuspid annuloplasty. Circulation 2006;114(Suppl):I582-7.

10. Sakon Y, Murakami T, Fujii H, Takahashi Y, Morisaki A, Yamane K et al. New insight into tricuspid valve anatomy from 100 hearts to reappraise annuloplasty methodology. Gen Thorac Cardiovasc Surg 2019;67:75864 .

11. Izumi C, Eishi K, Ashihara K, Arita T, Otsuji Y, Kunihara T et al. JCS/JSCS/JATS/JSVS 2020 Guidelines on the Management of Valvular Heart Disease. Circ J 2020; 84: 2037-119

12. Zoghbi WA, Enriquez-Sarano M, Foster E, Grayburn PA, Kraft CD, Levine RA et al. Recommendations for evaluation of the severity of native valvular regurgitation with two-dimensional and Doppler echocardiography. J Am Soc Echocardiogr 2003;16:777-802. 
13. Abe Y, Akamatsu K, Ito K, Matsumura Y, Shimeno K, Naruko T et al. Prevalence and prognostic significance of functional mitral and tricuspid regurgitation despite preserved left ventricular ejection fraction in atrial fibrillation patients. Circ J 2018;82:1451-8.

14. Rudski LG, Lai WW, Afilalo J, Hua L, Handschumacher MD, Chandrasekaran K et al. Guidelines for the echocardiographic assessment of the right heart in adults: a report from the American Society of Echocardiography endorsed by the European Association of Echocardiography, a registered branch of the European Society of Cardiology, and the Canadian Society of Echocardiography. J Am Soc Echocardiogr 2010;23:685-713.

15. McLaughlin VV, Archer SL, Badesch DB, Barst RJ, Farber HW, Lindner JR et al. ACCF/AHA 2009 expert consensus document on pulmonary hypertension: a report of the American College of Cardiology Foundation Task Force on Expert Consensus Documents and the American Heart Association developed in collaboration with the American College of Chest Physicians; American Thoracic Society, Inc.; and the Pulmonary Hypertension Association. J Am Coll Cardiol 2009;53:1573-619.

16. Lang RM, Bierig M, Devereux RB, Flachskampf FA, Foster E, Pellikka PA et al. Recommendations for chamber quantification: a report from the American Society of Echocardiography's Guidelines and Standards Committee and the Chamber Quantification Writing Group, developed in conjunction with the European Association of Echocardiography, a branch of the European Society of Cardiology. J Am Soc Echocardiogr 2005;18:1440-63.

17. Silver MD, Lam JH, Ranganathan N, Wigle ED. Morphology of the human tricuspid valve. Circulation 1971;43:333-48.

18. Shibata T, Takahashi Y, Sakon Y, Morisaki A, Murakami T. Shoulder point fitting method as a new universal tricuspid annuloplasty. Ann Thorac Surg 2018;106:e49-51.

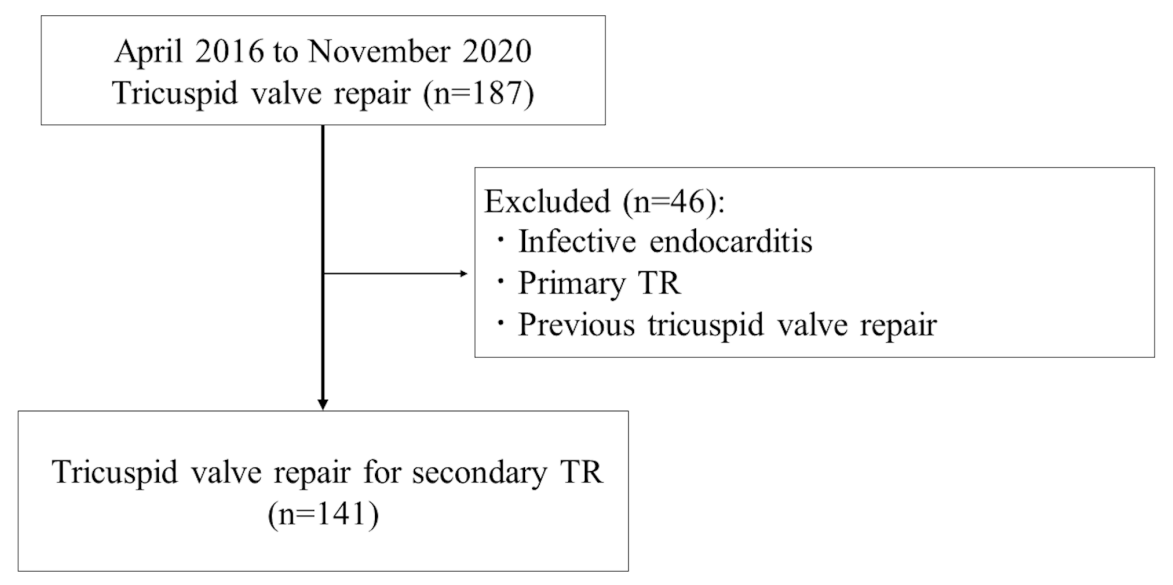


Fan-shaped chordae
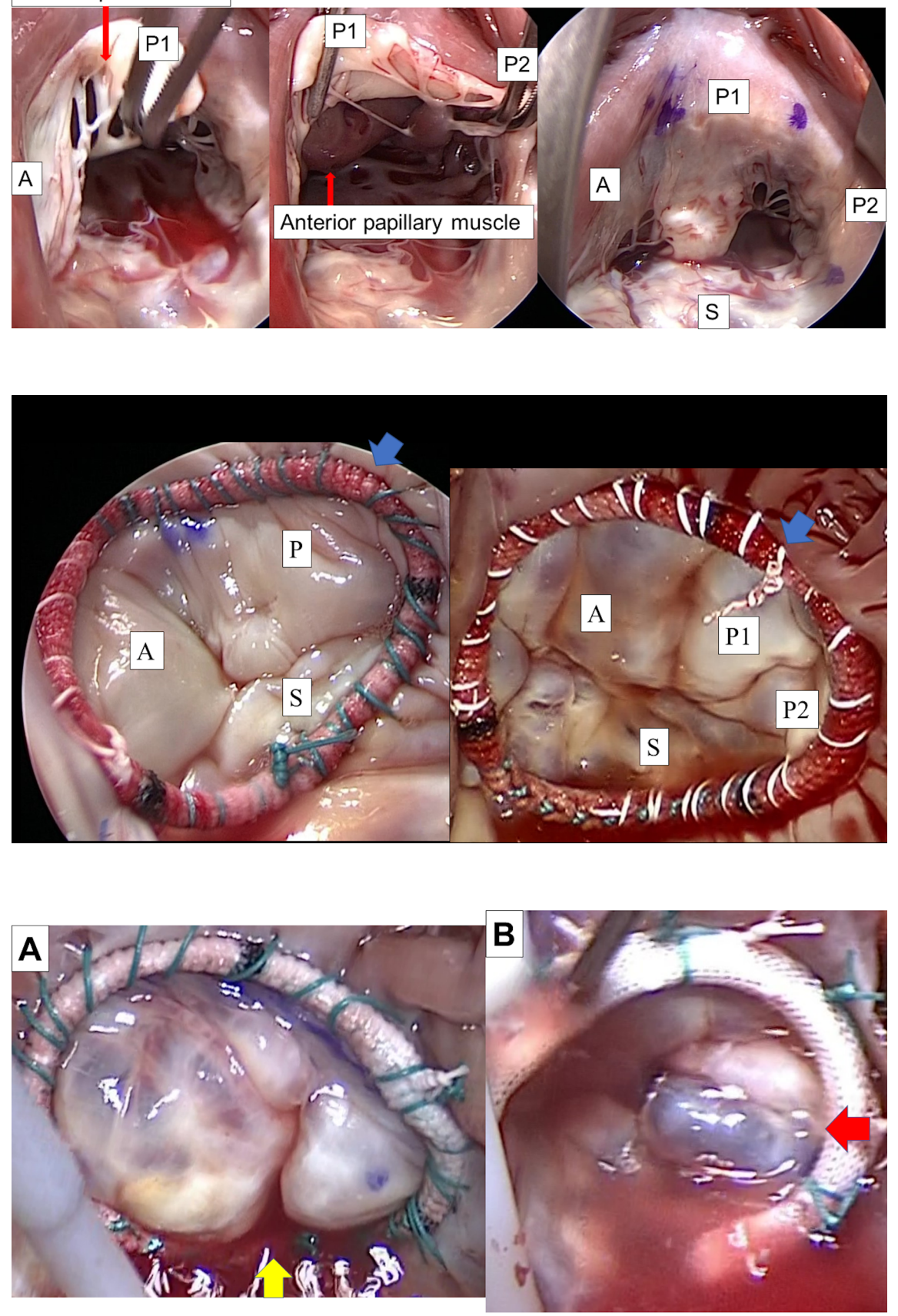